\title{
Examination of Patients' Regular Participation at an Obesity Center to Evaluate the Effects on Mental Status and Blood Parameters
}

\author{
Duygu İlke Yıldırım ${ }^{1, *}$, Mehmet Ali Eryılmaz ${ }^{2}$, Memduha Aydın ${ }^{3}$ \\ Departments of ${ }^{1}$ Family Medicine and ${ }^{2}$ General Surgery, Konya Training and Research Hospital, University of Health Sciences, Konya; ${ }^{3}$ Department of Psychiatry, \\ Faculty of Medicine, Selçuk University, Konya, Turkey
}

Background: Obesity is the main cause of type 2 diabetes, coronary artery disease, musculoskeletal disorders, some cancers, and mental disorders, and many other diseases leading to mortality. The aim of this study was to determine the effects of participation in an obesity center on patient mental status and blood parameters within 3 months and to show the relationship of this participation with depression, anxiety, and other parameters. Methods: This was a descriptive and cross-sectional study. Of 2,591 patients admitted to an obesity center between November 1, 2018 and November 1, 2019, 317 met the inclusion criteria. This study was a descriptive and cross-sectional study of the data from those 317 patients.

Results: Of the patients enrolled in the study, $90.5 \%$ were female and $9.5 \%$ were male. Weight, occupation, body mass index, body fat percentage, waist circumference, hip circumference, glycosylated hemoglobin (HbA1c), Beck Depression Scale, and Beck Anxiety Scale were important determinants in our univariate analyses associated with the regular receipt of center education. $\mathrm{HbA1c}$ (odds ratio, 1.661; 95\% confidence interval, $1.140-2.421 ; P=0.008$ ) was shown to be multivariate predictors of amount of participation in center education. Conclusion: These results support that regular participation in obesity center education has a positive effect on patients mental status, blood parameters, and anthropometric measurements. Thus, increasing the number of obesity centers is of great importance in treating obesity and improving obese patient mental status.
Received April 9, 2020

Reviewed May 1, 2020

Accepted June 15, 2020

${ }^{*}$ Corresponding author

Duygu İlke Yıldırım

https://orcid.org/0000-0002-3893-5173

Department of Family Medicine, Konya Training and Research Hospital, University of Health Sciences, Hacl Saban Mah. Meram Yeniyol Caddesi No. 97 PK: 42090, Meram, Konya, Turkey Tel: +90-332-2210000

Fax: +90-332-3236723

E-mail: azrailla@hotmail.com

Key words: Obesity, Depression, Anxiety, Biomarkers

\section{INTRODUCTION}

Obesity is the main cause of type 2 diabetes, coronary artery disease, musculoskeletal disorders, some cancers, mental disorders, and many other diseases causing mortality. ${ }^{1-3}$ The prevalence of obesity and depression across the world is rapidly increasing. Worldwide, 650 million people are obese, and 300 million are trying to cope with depression. ${ }^{4,5}$ A meta-analysis of 17 cross-sectional studies on adults showed a significant relationship between obesity and depression. ${ }^{6}$ Vogelzangs et al. ${ }^{7}$ showed that people with depression/anxiety disorders were $1.37,4.96,3.54$, and 4.75 times more likely to have stroke, angina pectoris, coronary heart disease, and myocardial infarction, respectively, than those without these diagnoses. In recent years, increasing evidence has been presented showing that these diseases are interrelated..$^{8-11}$

In order to prevent obesity in Turkey, 81 obesity centers have been opened in 34 provinces. The aim of these centers is to help patients reach their ideal weight, prevent patients from being directed to surgical operations, teach correct lifestyle changes, and identify the underlying problems of obesity. Patients with a body mass index (BMI) of $30 \mathrm{~kg} / \mathrm{m}^{2}$ and above are admitted to obesity centers. The patients are trained by physicians, dieticians, physio-

Copyright (C) 2020 Korean Society for the Study of Obesity

(a) This is an Open Access article distributed under the terms of the Creative Commons Attribution Non-Commercial License (https://creativecommons.org/licenses/by-nc/4.o/) which permits unrestricted non-commercial use, distribution, and reproduction in any medium, provided the original work is properly cited. 
therapists, psychologists, and the nurses in charge of the centers over a 3-month period. After 3 months of education, patients are monitored for 3 months to evaluate the effectiveness of the education.

The aim of this study was to analyze the association between the mental and physical scales and regular participation in a unique multidisciplinary obesity prevention program and to determine the independent predictors of regular participation.

\section{METHODS}

\section{Study population and design}

Of 2,591 patients who presented to the obesity center to participate in the obesity prevention program between November 1, 2018 and November 1, 2019, 317 patients were accepted into this obesity program and participated in our retrospective, descriptive, cross-sectional study. The necessary conditions for the acceptance to our obesity prevention program were: age $\geq 18$ years, BMI $\geq 30 \mathrm{~kg} / \mathrm{m}^{2}$, and approval from five different physicians (cardiologist, internal medicine specialist, psychiatrist, general surgeon, and physical therapist/rehabilitation specialist). Patients who fulfilled these conditions were evaluated by the responsible physician of the obesity center. The responsible physician of the obesity center made the final assessments to decide whether to accept the patients. Patients with major depression, heart failure, coronary artery disease, age under 18 years and any special conditions preventing third month follow-up visits were excluded. These are the common rules received by the Ministry of Health for all obesity centers in Turkey. All obesity centers in Turkey use the common program called "Obezit" as established by the Ministry. ${ }^{12}$

The inclusion criteria of this study were active participation in an obesity prevention center program and completion of anxiety/depression forms in the first month and third month. Individuals with psychoses, adjustment disorders, self-reported schizophrenia, and personality disorders were excluded from analysis after their acceptance to the center.

\section{Overall function and operation}

The obesity center is staffed full-time by five people, including a physician, nurse, dietician, psychologist, and secretary. Two physio- therapists attend the center for 2 hours, once per week. All healthcare providers of the obesity center receive obesity basic knowledge certificates and "Obezit" system basic knowledge certificate training. ${ }^{13}$

Training is given at the center 5 days per week. Each group consists of approximately 20 patients with obesity. Patients are called for outpatient visit at least once a year after all education was completed. In the training sessions, patients were directed to a healthy lifestyle as suggested by the Ministry of Health in all obesity centers in Turkey. Patients are checked every month by the nurse and blood tests are peformed. Patients with hypertension, diabetes, hypothyroidism/hyperthyroidism and other similar diseases are also treated by the center physician. These services are covered by state health insurance.

\section{Organization and contents of education session}

All obesity center employees receive 1-week specific training from the Ministry of Health. Patients are first oriented and educated on the pathophysiology of obesity by the physician of the obesity center. Individualized healthy lifestyle habits are suggested following the interview between the physician and the patients. A dietician arranges proper dietary recommendations, a psychologist investigates underlying improper predispositions, and a physiotherapist provides training for the correct physical activity. A nurse monitors and motivates patients in monthly follow-ups. There are several pamphlets prepared by the center staff for patient education during follow-up.

The training topics in this program were health and life, health and illness, healthy eating, obesity, obesity and life, harms of excess fat and weight, perceptions and emotions that govern individuals, and image (body) perception in obesity. Education sessions were operated as one-to-group sessions. The groups were formed homogeneously according to the BMI values. Patients with a BMI 30.00$39.99 \mathrm{~kg} / \mathrm{m}^{2}$ were divided into one group, those with BMI 40.00 $49.99 \mathrm{~kg} / \mathrm{m}^{2}$ were in another group, and patients with BMI $\geq 50.00$ $\mathrm{kg} / \mathrm{m}^{2}$ were allocated to a third group. Each session lasted 1 hour.

According to the Turkish Society of Endocrinology and Metabolism guideline, patients with a BMI $\geq 30-34.99 \mathrm{~kg} / \mathrm{m}^{2}$ were defined as slightly obese, $35.00-39.99 \mathrm{~kg} / \mathrm{m}^{2}$ as moderately obese, $40.00-49.99 \mathrm{~kg} / \mathrm{m}^{2}$ as morbidly obese, and $\geq 50.00 \mathrm{~kg} / \mathrm{m}^{2}$ as super 
obese. ${ }^{14}$ The sociodemographic data form, the Beck Depression Scale (BDS), and Beck Anxiety Scale (BAS), which were routinely administered to all patients admitted to the obesity center at first arrival, were readministered to all patients at the third month. The blood parameters that were routinely measured at the center for 3 months and the BDS and BAS scales, together with the data collection form, were evaluated retrospectively. Patients at the center participated in twelve education sessions held at least 3 days per week for the first month. Patients also participated in at least six sessions during the second month and at least three sessions during third month. Patients were classified in our center according to participation in the education sessions. Patients who did not participate in half of the 12 education sessions during the first 1 month, those who did not participate in half of the six sessions during the second month, and those who did not participate in any of the three sessions during the third month were included in the nonparticipating group. The parameters and mental status of the patients who did and did not participate in the education sessions were measured after 3 months and compared with the data recorded upon arrival.

The study was conducted under the original Declaration of Helsinki and its later amendments or comparable ethical standards and was approved by the local Ethics Committee of Selçuk University, Faculty of Medicine (No. 2019/375, Date: 25.12.2019). All participants gave written informed consent.

\section{Data collection tools}

\section{Sociodemographic data collection form}

All patients admitted to the obesity center were asked to complete a form to determine their sociodemographic characteristics. This form included questions about the patients' age, sex, height, weight, BMI, marital status, educational status, place of residence, social security, and income levels.

\section{Beck Depression Scale}

This scale was developed by Beck et al. ${ }^{15}$ in 1961 . The scale is a Likert-type self-assessment scale used to determine the patient's level and risk of depressive symptoms. The Turkish validity and reliability study was performed by Hisli in $1988 .{ }^{16}$ The scale consists of 21 questions. The highest score is 63 and the lowest score is 0.
According to the scores obtained from the scale: 0-9 points, normal; $10-16$ points, mild depression; $17-29$ points, moderate depression; and 30-63 points, severe depression. Seventeen points was considered as the cut-off value, and scores above 17 were associated with depression in $90 \%$ of cases. ${ }^{15}$

\section{Beck Anxiety Scale}

This scale was developed by Beck et al. ${ }^{17}$ in 1988 and the Turkish validity and reliability study was conducted by Ulusoy et al. ${ }^{18}$ in 1998. The BAS is a Likert-type scale consisting of 21 items in total. For each item, the lowest score is 0 and the highest score is 3 . The scale determines the levels of bothersome distress the patient experienced during the last week. The maximum score of the scale is 63 points. High scores indicate that the level of anxiety is high. According to the scores taken from the scale: $8-15$ points, mild anxiety; $16-25$ points, moderate anxiety; and 26-63 points, severe anxiety.

\section{Statistical analysis}

Statistical results were evaluated using the IBM SPSS ver. 22.0 (IBM Corp., Armonk, NY, USA). Frequency, percentage, mean \pm standard deviation, range values were used as descriptive statistics to evaluate the data obtained from the study. The t-test and logistic regression analysis were used to compare the averages of the continuous variables of the data. Pearson correlation analysis was used to investigate correlations. The normality of the data was checked using the Kolmogorov-Smirnov normality test. Multiple logistic regression analysis using the backward logistical regression method was applied to determine the best predictors that affected the regular participation of the patients after adjusting for all possible confounding factors. Along with all variables of known clinical importance, any variable that had a univariate test $P$-value $<0.05$ was accepted as a candidate for a multivariable model. All analyses were conducted within a $95 \%$ confidence interval.

\section{RESULTS}

Of the patients enrolled in the study, $90.5 \%$ were female and $9.5 \%$ were male. The mean age of the patients was $48.12 \pm 11.05$ years. Patients aged $19-49$ years were $49.9 \%(n=158)$, and those 
aged 66 years or older were $2.8 \%(n=9)$. When the patients were evaluated according to BMI, 32.5\% ( $\mathrm{n}=103)$ were slightly obese, $34.7 \%(n=110)$ were moderately obese, $29 \%(n=92)$ were morbidly obese, and $3.8 \%(n=12)$ were super obese. Sixty percent $(\mathrm{n}=190)$ of the patients were elementary school graduates, and $85.8 \%(n=272)$ were married. The patients who attended the center for education regularly were $56.2 \%(\mathrm{n}=178)$, and those who did not attend the center regularly were $43.8 \%(n=139)$.

The majority $(81.7 \%, n=259)$ of the patients were housewives. When the income status of the patients was evaluated, $58.3 \%$ ( $\mathrm{n}=$ 185 ) were found to have above average income status. According to the first BDS results, $31.8 \%(\mathrm{n}=101)$ of patients were evaluated as normal, $28.4 \%(\mathrm{n}=90)$ had mild depression, $27.8 \%(\mathrm{n}=88)$ had moderate depression, and $12 \%(\mathrm{n}=38)$ of patients had severe depression. According to BDS results at 3 months, $41 \%(n=130)$ of patients were evaluated as normal, 29.3\% $(\mathrm{n}=93)$ had mild depression, $22.1 \%(\mathrm{n}=70)$ had moderate depression, and 7.6\% $(\mathrm{n}=24)$ of patients had severe depression. According to the initial BAS results, $8.2 \%(\mathrm{n}=26)$ had no anxiety, $8.8 \%(\mathrm{n}=28)$ had mild anxiety, $24.3 \%(n=77)$ had moderate anxiety, and 58.7\% $(n=186)$ had severe anxiety. According to the BAS results at 3 months, $22.4 \%$ ( $n=$ $71)$ of the patients had no anxiety, $29.3 \%(n=93)$ had severe anxiety (Table 1 ).

When we evaluated the mean scores of the patients in the center according to their attendance status, the mean scores for depression and anxiety in the first month were significantly higher, and these were significantly lower by the third month in patients who continued center education compared with those who did not $(P<0.001)$. The depression and anxiety scores of patients who continued with the education were significantly higher at the beginning than in those who did not attend the education. BMI in the first month

Table 1. Sociodemographic characteristics of patients ( $n=317)$

\begin{tabular}{lc}
\hline Characteristics & Value \\
\hline Sex & \\
Female & $287(90.5)$ \\
Male & $30(9.5)$ \\
Age (yr) & $48.12 \pm 11.05(19-75)$ \\
$19-49$ & $158(49.9)$ \\
$50-65$ & $150(47.3)$ \\
$\geq 66$ & $9(2.8)$ \\
\hline
\end{tabular}

(Continued to the next)
Table 1. Continued

\begin{tabular}{|c|c|}
\hline Characteristics & Value \\
\hline $\mathrm{BMI}\left(\mathrm{kg} / \mathrm{m}^{2}\right)$ & $38.45 \pm 5.69(30.00-58.50)$ \\
\hline \multicolumn{2}{|l|}{ BMI categorical } \\
\hline Class I obesity & $103(32.5)$ \\
\hline Class II obesity & $110(34.7)$ \\
\hline Class III obesity & $92(29.0)$ \\
\hline Super obese & $12(3.8)$ \\
\hline \multicolumn{2}{|l|}{ Educational level } \\
\hline Illiterate & $17(5.3)$ \\
\hline Elementary school & $190(60.0)$ \\
\hline High school & $54(17.0)$ \\
\hline$\geq$ University & $56(17.7)$ \\
\hline \multicolumn{2}{|l|}{ Marital status } \\
\hline Married & $272(85.8)$ \\
\hline Single/divorced & $45(14.2)$ \\
\hline \multicolumn{2}{|l|}{ Continuity obesity center } \\
\hline Yes & $178(56.2)$ \\
\hline No & $139(43.8)$ \\
\hline \multicolumn{2}{|l|}{ Occupation } \\
\hline Housewife & $259(81.7)$ \\
\hline Retired & $27(8.5)$ \\
\hline Artisan/self-employment & $8(2.6)$ \\
\hline Public personnel & $21(6.6)$ \\
\hline Private sector & $2(0.6)$ \\
\hline \multicolumn{2}{|l|}{ Income status } \\
\hline Low & $13(4.1)$ \\
\hline Middle & $119(37.6)$ \\
\hline Good & $185(58.3)$ \\
\hline \multicolumn{2}{|l|}{ BDS (1st month doctor visit) } \\
\hline Normal & $101(31.8)$ \\
\hline Mild depression & $90(28.4)$ \\
\hline Moderate depression & $88(27.8)$ \\
\hline Severe depression & $38(12.0)$ \\
\hline \multicolumn{2}{|l|}{ BDS (3rd month doctor visit) } \\
\hline Normal & $130(41.0)$ \\
\hline Mild depression & $93(29.3)$ \\
\hline Moderate depression & $70(22.1)$ \\
\hline Severe depression & $24(7.6)$ \\
\hline \multicolumn{2}{|l|}{ BAS (1st month doctor visit) } \\
\hline Normal & $26(8.2)$ \\
\hline Mild anxiety & $28(8.8)$ \\
\hline Moderate anxiety & $77(24.3)$ \\
\hline Severe anxiety & $186(58.7)$ \\
\hline \multicolumn{2}{|l|}{ BAS (3rd month doctor visit) } \\
\hline Normal & $71(22.4)$ \\
\hline Mild anxiety & $75(23.7)$ \\
\hline Moderate anxiety & $78(24.6)$ \\
\hline Severe anxiety & $93(29.3)$ \\
\hline
\end{tabular}

Values are presented as number (\%) or mean \pm standard deviation (range). BMI, body mass index; BDS, Beck Depression Scale; BAS, Beck Anxiety Scale. 
Table 2. Comparison of clinical, mental, and laboratory parameters by patients' attendance to the obesity center

\begin{tabular}{|c|c|c|c|c|c|c|}
\hline \multirow{2}{*}{ Variable } & \multicolumn{2}{|c|}{ Patient with continuity in center education } & \multicolumn{2}{|c|}{ Control } & \multirow{2}{*}{$P^{*}$ (baseline) } & \multirow{2}{*}{$P^{\dagger}$ (3 months) } \\
\hline & Baseline & 3 Months & Baseline & 3 Months & & \\
\hline BDS & $17.32 \pm 11.67$ & $8.84 \pm 7.06$ & $14.58 \pm 10.24$ & $17.92 \pm 9.80$ & 0.039 & $<0.001$ \\
\hline BAS & $33.62 \pm 16.84$ & $11.30 \pm 6.80$ & $28.87 \pm 15.59$ & $31.60 \pm 14.79$ & 0.019 & $<0.001$ \\
\hline $\mathrm{BMl}\left(\mathrm{kg} / \mathrm{m}^{2}\right)$ & $39.45 \pm 5.90$ & $36.85 \pm 5.68$ & $37.16 \pm 5.14$ & $37.65 \pm 5.09$ & $<0.001$ & 0.073 \\
\hline $\mathrm{BFP}(\%)$ & $45.10 \pm 5.21$ & $42.00 \pm 6.06$ & $42.86 \pm 5.96$ & $43.00 \pm 5.98$ & $<0.001$ & 0.024 \\
\hline $\mathrm{WC}(\mathrm{cm})$ & $110.10 \pm 11.30$ & $102.83 \pm 10.66$ & $106.60 \pm 14.08$ & $106.41 \pm 13.93$ & 0.025 & 0.010 \\
\hline $\mathrm{HC}(\mathrm{cm})$ & $128.94 \pm 11.60$ & $122.29 \pm 11.05$ & $125.17 \pm 11.37$ & $125.32 \pm 10.54$ & 0.004 & 0.008 \\
\hline $\mathrm{HbA1c}(\%)$ & $6.01 \pm 0.82$ & $5.67 \pm 0.49$ & $5.78 \pm 0.64$ & $6.15 \pm 0.60$ & 0.048 & $<0.001$ \\
\hline $\mathrm{HDL}-\mathrm{C}(\mathrm{mg} / \mathrm{dL})$ & $51.98 \pm 12.50$ & $51.29 \pm 8.10$ & $50.58 \pm 9.40$ & $48.54 \pm 8.76$ & 0.409 & 0.004 \\
\hline LDL-C (mg/dL) & $141.52 \pm 33.80$ & $140.21 \pm 28.74$ & $137.87 \pm 33.95$ & $150.44 \pm 30.72$ & 0.193 & $<0.001$ \\
\hline Triglyceride (mg/dL) & $155.54 \pm 77.48$ & $142.24 \pm 62.55$ & $147.41 \pm 63.01$ & $154.34 \pm 58.62$ & 0.817 & 0.035 \\
\hline
\end{tabular}

Values are presented as mean \pm standard deviation.

${ }^{*}$ Statistical analysis was done by Mann-Whitney U-test for baseline values; 'Data analysis was done by Mann-Whitney U-test for third month values.

BDS, Beck Depression Scale; BAS, Beck Anxiety Scale; BMI, body mass index; BFP, body fat percentage; WC, waist circumference; HC, hip circumference; HbA1C, glycosylated hemoglobin; HDL-C, high-density lipoprotein cholesterol; LDL-C, low-density lipoprotein cholesterol.

Table 3. Univariate logistic regression analysis of demographic characteristics and laboratory parameters at the first month by continuing obesity center trainings

\begin{tabular}{lcr}
\hline Variable & OR (95\% CI) & \multicolumn{1}{c}{$P$} \\
\hline Weight $(\mathrm{kg})$ & $1.020(1.005-1.036)$ & 0.010 \\
Occupation (housewife vs. others) & $2.268(1.268-4.058)$ & 0.006 \\
BMI $\left(\mathrm{kg} / \mathrm{m}^{2}\right)$ & $1.079(1.034-1.126)$ & $<0.001$ \\
BFP $(\%)$ & $1.076(1.032-1.122)$ & 0.001 \\
WC $(\mathrm{cm})$ & $1.023(1.004-1.042)$ & 0.016 \\
HC $(\mathrm{cm})$ & $1.029(1.009-1.050)$ & 0.005 \\
HbA1c $(\%)$ & $1.564(1.121-2.181)$ & 0.008 \\
BDS & $1.023(1.002-1.045)$ & 0.032 \\
BAS & $1.018(1.004-1.032)$ & 0.011 \\
\hline
\end{tabular}

$\mathrm{OR}$, odds ratio; $\mathrm{Cl}$, confidence interval; $\mathrm{BMI}$, body mass index; $\mathrm{BFP}$, body fat percentage; WC, waist circumference; $\mathrm{HC}$, hip circumference; HbA1c, glycosylated hemoglobin; BDS, Beck Depression Scale; BAS, Beck Anxiety Scale.

was significantly higher $(P<0.001)$, but was significantly lower in the third month $(P=0.024)$ in patients who continued with center education compared with those who did not. The average waist and hip circumferences in the first month were significantly higher $(P=0.01)$ and were significantly lower in the third month $(P=0.008)$ in patients who continued center education compared with those who did not. Mean glycosylated hemoglobin (HbAlc) level in the first month was significantly higher $(P=0.048)$ and was significantly lower in the third month $(P<0.001)$ in patients who continued with center education compared with those who did not. The mean high-density lipoprotein cholesterol (HDL-C) level was significantly higher $(P=0.004)$, and mean low-density lipoprotein cholesterol (LDL-C; $P<0.001)$ and triglyceride levels $(P=0.035)$ were signif-
Table 4. Multivariate analysis showing independent determinants of patients with continuity in center education

\begin{tabular}{lcc}
\hline Variable & $\mathrm{OR}(95 \% \mathrm{Cl})$ & $P$ \\
\hline $\mathrm{HbA1c}(\%)$ & $1.661(1.140-2.421)$ & 0.008 \\
\hline OR, odds ratio; $\mathrm{Cl}$, confidence interval; HbA1c, glycosylated hemoglobin.
\end{tabular}

icantly lower in the third month in patients who continued with center education than in those who did not (Table 2).

The univariate and multivariate logistic regression determinants of continuation with obesity center education are shown in Tables 3 and 4. Weight, occupation, BMI, body fat percentage (BFP), waist circumference, hip circumference, HbAlc, BDS, and BAS were important determinants of continuation with obesity center education in our univariate analyses (Table 3). HbA1c (odds ratio, 1.661; 95\% confidence interval, 1.140-2.421; $P=0.008)$ was defined as multivariate predictors affecting continuation with obesity center education (Table 4).

\section{DISCUSSION}

According to our results, increased patient income levels and decreased BFP, BAS, and $\mathrm{HbAlc}$ values were associated with increased participation in obesity center education. There was a significant positive relationship between depression and anxiety, weight, BMI, waist circumference, hip circumference, $\mathrm{HbAlc}$, and LDL-C. There was a significant positive relationship between anxiety and depres- 
sion, weight, BMI, waist circumference, hip circumference, and $\mathrm{HbAlc}$ and a negative relationship between anxiety and HDL-C. In patients who continued with center education, the mean values of BDS, BAS, waist circumference, hip circumference, HbAlc, LDL-C, and triglycerides were significantly lower, and HDL-C values were significantly higher in the third month measurements.

In our study, the depression and anxiety levels of patients who were evaluated in the $3 \mathrm{rd}$ month were found to be significantly lower than those measured in the first month. Although other studies have demonstrated a relationship between obesity and depression, few studies have shown a definite relationship between anxiety and obesity. ${ }^{19-21}$ Another study with 94 female participants enrolled in family health centers concluded that obesity increased the risk of anxiety and depression. ${ }^{22}$ According to United States National Health and Nutrition study data, there is a positive relationship between $\mathrm{BMI}$ and depression, which is significantly noticeable when $\mathrm{BMI}$ is $30 \mathrm{~kg} / \mathrm{m}^{2}$ or above. ${ }^{23}$ Given that our study was conducted in an obesity center, the BMI of all patients in the study was at least $30 \mathrm{~kg} / \mathrm{m}^{2}$. As a result, the risk of depression and anxiety decreased as the patients' BMI values decreased. In our study, the depression level of $59 \%$ of patients with obesity was above the threshold ( $\geq 10$ points), and the anxiety level of $91.8 \%$ was above the threshold ( $\geq 8$ points) in the first month. In one study conducted with 50 patients with obesity admitted to an endocrinology outpatient clinic, $36.2 \%$ of patients had depression and $3.4 \%$ had anxiety disorder. ${ }^{24}$ In a second study with 94 female participants, $88.9 \%$ of overweight and obese patients were diagnosed as having anxiety; 83.3\% were diagnosed as having depression. ${ }^{22}$ In the study by Fox et $\mathrm{al}^{25}$, which was conducted with a total of 102 adolescents, $91 \%$ of patients with depression were morbidly obese; and 94\% of those with anxiety were morbidly obese. In addition to these results, there are studies indicating that obesity and depression are more common in women. The fact that our study was conducted in an obesity center and that the education took place during working hours may have facilitated the participation of the women, $81.7 \%$ of whom were housewives.

In our study, we found that there was a positive relationship between BFP and depression/anxiety. Studies in the literature have also shown a relationship between BFP and depression. ${ }^{6,26}$ In a study conducted with 30 male patients, the male patients with a
BFP value of 15 and depression was determined to be $25.2 \%$, and the male patients with a BFP value of 15 without depression was determined as $25.3 \%$. There was no significant association between the BFP values of these two groups. ${ }^{27}$ According to the results of our study, the education received at the center positively affected and significantly reduced the BFP and depression and anxiety levels of the patients by the third month.

Fourteen prospective studies were included in a systematic review by Gill et al. ${ }^{28}$ who examined a total of 2,058 articles. Of the studies, $98 \%$ reported severe reductions in depressive symptoms 2-3 years after bariatric surgery. All studies indicated statistically significant decreases in depressive symptoms at the end of the study. According to the results of eight studies, the severity of anxiety symptoms decreased during $\geq 24$ months of follow-up, and postoperative weight loss did not predict changes in anxiety symptoms. In our study, the depression and anxiety levels of patients who continued with center education decreased significantly within 3 months, and a positive correlation between BMI and BDS and BAS was found. Our study also predicted the decrease in depression and anxiety levels after weight loss in patients who attended obesity center education sessions regularly for 3 months. Our study is the first to evaluate the effects of an obesity center on patients' mental status and blood parameters. We show that obesity surgery, which is very popular and often preferred in the treatment of obesity worldwide, is not the only solution. According to the results of the study, we can recommend obesity centers as an independent treatment tool for patients to lose weight and improve mental status.

Our study had some limitations. The results of the study were not compared with a similar study because our obesity center is one of a few centers in Turkey, and no other studies have been conducted in obesity centers. The fact that the majority of the population comprised female patients prevented generalization. Scales such as BDS and BAS do not take into account psychosocial factors. We suggest that future prospective studies should be conducted in more homogenous, dispersed populations with a longer follow-up period and take into account psychosocial factors.

\section{CONFLICTS OF INTEREST}

The authors declare no conflict of interest. 


\section{AUTHOR CONTRIBUTIONS}

Study concept and design: DIY and MAE; acquisition of data: DIY and MAE; analysis and interpretation of data: DIY; drafting of the manuscript: DIY; critical revision of the manuscript: all authors; statistical analysis: DIY; administrative, technical or material support: DIY and MAE; and study supervision: all authors.

\section{REFERENCES}

1. Ghoorah K, Campbell P, Kent A, Maznyczka A, Kunadian V. Obesity and cardiovascular outcomes: a review. Eur Heart J Acute Cardiovasc Care 2016;5:77-85.

2. Kabadi SM, Lee BK, Liu L. Joint effects of obesity and vitamin $\mathrm{D}$ insufficiency on insulin resistance and type 2 diabetes: results from the NHANES 2001-2006. Diabetes Care 2012;35: 2048-54.

3. Molosankwe I, Patel A, José Gagliardino J, Knapp M, McDaid D. Economic aspects of the association between diabetes and depression: a systematic review. J Affect Disord 2012;142 Suppl:S42-55.

4. Konttinen H, Van Strien T, Männistö S, Jousilahti P, Haukkala A. Depression, emotional eating and long-term weight changes: a population-based prospective study. Int J Behav Nutr Phys Act 2019;16:1-11.

5. Konttinen $\mathrm{H}$. Emotional eating and obesity in adults: the role of depression, sleep and genes. Proc Nutr Soc 2020 Mar 26 [Epub]. https://doi.org/10.1017/S0029665120000166

6. Luppino FS, de Wit LM, Bouvy PF, Stijnen T, Cuijpers P, Penninx BW, et al. Overweight, obesity, and depression: a systematic review and meta-analysis of longitudinal studies. Arch Gen Psychiatry 2010;67:220-9.

7. Vogelzangs N, Seldenrijk A, Beekman AT, van Hout HP, de Jonge P, Penninx BW. Cardiovascular disease in persons with depressive and anxiety disorders. J Affect Disord 2010;125: 241-8.

8. Thormann J, Chittka T, Minkwitz J, Kluge M, Himmerich H. Obesity and depression: an overview on the complex interactions of two diseases. Fortschr Neurol Psychiatr 2013;81:14553.
9. Hong GW, Hong SM. Relationships among body mass index, body image, and depression in Korean adults: Korea National Health and Nutrition Examination Survey 2014 and 2016. J Obes Metab Syndr 2019;28:61-8.

10. Pan A, Sun Q, Czernichow S, Kivimaki M, Okereke OI, Lucas $\mathrm{M}$, et al. Bidirectional association between depression and obesity in middle-aged and older women. Int J Obes (Lond) 2012;36:595-602.

11. Afari N, Noonan C, Goldberg J, Roy-Byrne P, Schur E, Golnari $G$, et al. Depression and obesity: do shared genes explain the relationship? Depress Anxiety 2010;27:799-806.

12. Obesit Education Program [Internet]. Ankara:Republic of Turkey Ministry of Health [cited 2020 Jun 24]. Available from: https://www.obezit.org/bilissel-egitim-seminerler/

13. Obesit Certification Program [Internet]. Ankara: Republic of Turkey Ministry of Health [cited 2020 Jun 24]. Available from: https://sertifika.obezit.org/

14. Erem C. Prevalence of overweight and obesity in Turkey. IJC Metab Endocr 2015;8:38-41.

15. Beck AT, Ward CH, Mendelson M, Mock J, Erbaugh J. An inventory for measuring depression. Arch Gen Psychiatry 1961; 4:561-71.

16. Hisli N. A reliability and validity study of Beck Depression Inventory in a university student sample. J Psychol 1989;7:3-13.

17. Beck AT, Epstein N, Brown G, Steer RA. An inventory for measuring clinical anxiety: psychometric properties. J Consult Clin Psychol 1988;56:893-7.

18. Ulusoy M, Sahin NH, Erkmen H. The Beck Anxiety Inventory: psychometric properties. J Cogn Psychother 1998;12:163-72.

19. Ha H, Han C, Kim B. Can obesity cause depression? Using pseudo panel analysis. Cell 2017;10:5061-8720.

20. Gunalay S, Taskiran E, Demir B, Erdem S, Mergen H, Akar H. Relationship between treatment modalities, glycemic control, and diabetes complications with risk of depression and anxiety in type 2 diabetes mellitus patients. FNG Bilim Tip Dergisi 2016;2:16-9.

21. Gomes AP, Soares AL, Menezes AM, Assunção MC, Wehrmeister FC, Howe LD, et al. Adiposity, depression and anxiety: interrelationship and possible mediators. Rev Saude Publica 2019;53:103. 
22. Emre N, Öner M. The relationship between obesity, quality of life and psychological state in women living in rural areas. Turk J Family Pract 2018;22:176-84.

23. Johnson CL, Paulose-Ram R, Ogden CL, Carroll MD, KruszonMoran Deanna, Dohrmann SM, et al. National health and nutrition examination survey: analytic guidelines, 1999-2010. Vital Health Stat 2 2013;(161):1-24.

24. Deveci A, Demet MM, Özmen B, Özmen E, Hekimsoy Z. Psychopathology, alexithymia, and self-esteem in obese patients. Anadolu Psikiyatri Derg 2005;6:84-91.

25. Fox CK, Gross AC, Rudser KD, Foy AM, Kelly AS. Depression, anxiety, and severity of obesity in adolescents: is emotional eating the link? Clin Pediatr (Phila) 2016;55:1120-5.

26. Yu NW, Chen CY, Liu CY, Chau YL, Chang CM. Association of body mass index and depressive symptoms in a Chinese community population: results from the Health Promotion Knowledge, Attitudes, and Performance Survey in Taiwan. Chang Gung Med J 2011;34:620-7.

27. Gonoodi K, Moslem A, Darroudi S, Ahmadnezhad M, Mazloum Z, Tayefi M, et al. Serum and dietary zinc and copper in Iranian girls. Clin Biochem 2018;54:25-31.

28. Gill H, Kang S, Lee Y, Rosenblat JD, Brietzke E, Zuckerman H, et al. The long-term effect of bariatric surgery on depression and anxiety. J Affect Disord 2019;246:886-94. 